\title{
SEISMIC RESISTANT JOINTS FOR REINFORCED CONCRETE STRUCTURES
}

\author{
R.C. Fenwick*
}

\begin{abstract}
:
The theory of shear resistance of beam column joints is described and the results of two tests on beam column units in which bond plates were used in the joints are presented. Potential advantages for the use of this form of construction arise from the reduction in reinforcement congestion in the joint zone and the elimination of bond stress limitations on beam reinforcement passing through interior joints. These two factors in some situations allow structural member sizes to be reduced, and simpler reinforcement arrangements to be used as bar sizes are not restricted. A number of tentative recommendations are made for the design of this form of joint.
\end{abstract}

\section{INTRODUCTION:}

During the last decade considerable progress has been made on understanding the behaviour of reinforced concrete beam column joints subjected to severe seismic loading conditions. As a result of research, which has included many tests on these joints, design methods have been established and codified, and these may be used with considerable confidence by a structural designer.

In the N.Z. concrete code two different types of beam column joint have been considered. 1 The first of these is the conventional or standard joint, where beam hinges may be expected to form adjacent to the column faces. The second is the elastic joint, where the potential beam hinges are located some distance from the column face. Here the joint and adjacent beam regions are detailed so that this region remains elastic. Both types of joint have particular advantages and disadvantages associated with them. The research reported in this paper considers a further form of joint which would appear to have some structural advantage over the other two forms in certain situations. With its use the joint zone remains elastic but the potential beam hinge can form close to the column face.

With the conventional beam column joint it has been found that joint zone stirrups are required to carry the full shear unless the column is under a moderate or high axial load. To satisfy this requirement a large area of joint zone stirrup reinforcement is required, which gives serious steel congestion problems. The practical solution to this difficulty is to increase the joint zone size, and reduce the joint zone shear by using large beams with low steel percentages. Typically, beam flexural steel percentages are in the range of 0.8 to 1.1 percent. Thus one potential disadvantage of conventional joints is that large beams with low steel percentages are required. A further practical difficulty arises from anchoring the flexural reinforcement through the joint. With plastic hinges forming on each side of interior columns the beam flexural reinforcement can pass from a state of

* Senior Lecturer, Civil Engineering Department, University of. Auckland yield or near yield in compression on one side to yield in tension on the other side. Thus each bar tends to act as a doublepowered hack-saw through the joint. If slip results severe stiffness degradation occurs, which is followed after a few further cycles by strength degradation. To control this potential form of failure it is necessary to limit the bond stress on the beam flexural reinforcement, by using either small diameter bars, large columns or a combination of both. This situation aggravates steel congestion problems, and forces the designer to use larger members than he might otherwise need.

The elastic joint overcomes some of the disadvantages described above, but it cannot be used in many situations. With this form of joint the potential plastic hinges must be located a distance of not less than the beam depth or $500 \mathrm{~mm}$ from the column face. The potential hinge is fixed in the chosen location by bending down or terminating some of the flexural steel. The flexural reinforcement in the region adjacent to the joint has to be proportioned to remain elastic under strain hardening conditions in the hinge zone. For the case of a beam where a considerable portion of the design moment comes from gravity effects, the moment gradient close the column face can be too steep to allow the hinge to be located in the required position. In addition to this some detailing difficulties can occur with bar anchorages and the position of bent up reinforcement in the potential hinge zones. However, where elastic joints can be used less joint zone shear reinforcement is required, so that steel congestion is reduced and smaller sized beams may be used. The size limitation on flexural reinforcement is also relaxed because the joint is not degraded by yielding of the reinforcement.

The new form of joint described in this paper behaves in a manner similar to an elastic joint, but the potential beam hinge can be located close to the column face. Bond failure of the beam reinforcement through the joint is prevented by the use of bond plates which are welded to the beam flexural steel on each side of the joint. To keep it elastic, additional smali diameter bars are welded to the beam flexural reinforcement over this region. With this arrangement the 
size of structural members may be reduced, and reinforcement arrangements may be simplified by using larger diameter steel bars. Potential direct advantages of this form of joint arise from the smaller member sizes which result from the use of higher steel percentages and larger diameter bars. As bond through the joint is not a problem the restrictions relating to column dimension and beam reinforcement diameters do not apply, so that in some situations smaller columns may be used. Indirect advantages may arise from the reduced dimensions of the structural members giving a lower building stiffness and consequently a lower seismic design load.

\section{SHEAR RESISTANCE IN BEAM COLUMN JOINTS:}

The forces acting on a joint are shown in Figure 1. The horizontal shear force arises from the action of the beam flexural forces and column shear, and it is given by the expression

$\mathrm{v}_{j h}=\mathrm{c}_{1}+\mathrm{T}_{2}-\mathrm{v}_{3}$

where $C_{1}$ and $T_{2}$ are the beam flexural forces and $V_{3}$ is the shear force in the column. A similar expression may be derived for the vertical shear in the joint $v_{j v}$.

In designing for seismic action it is important to identify the maximum joint forces, and consequently the values of the beam flexural forces have to be assessed allowing for the actual beam reinforcement, with due allowance for overstrength and strain hardening which may occur under repeated plastic hinging.

Two principle actions have been identified in providing the joint zone shear resistance. The first of these, which provides the shear ascribed to the concrete, is diagonal strut action, and the second, which requires horizontal and vertical shear reinforcement, is panel truss action 2,3 . Other actions, such as the shear resisted by dowel action, are believed to be small and have not been considered.

The forces associated with the diagonal strut and panel truss actions are shown in Fig. 2 .

As illustrated, with diagonal strut action a diagonal compression force $D_{C}$ acts across the joint and it is sustained at the corners by horizontal and vertical flexural forces from the intersecting beam and column. The horizontal force from the beam is made up of two components, namely, the flexural compression force in the concrete $\mathrm{C}_{\mathrm{Cl}}$, and the bond force transmitted to the beam reinforcement to the concrete in the compression corner of the joint $\Delta \mathrm{T}_{\mathrm{b}}$. The vertical

force consists of all or part of the compression force in the concrete, induced by the column flexural and axial load $\mathrm{C}_{\mathrm{C} 3}$, together with the bond force sustained in the compression corner of the concrete from the column tension reinforcement $\Delta \mathrm{T}_{\mathrm{COl}}{ }^{\circ}$ The equilibrium diagram for these forces is shown in Fig. 2 .

The direction of the diagonal compression force in the concrete is fixed by the location of the forces in the beam and column at the joint. Increasing the column axial load moves the resultant of the column compression force towards the centre of the column, thus increasing the angle $\beta$. However, the effect is small unless the axial load is high, and for practical purposes the direction of the compression force may be assumed to be along the joint diagonal.

Provided plastic hinges do not form close to the column faces of the joint a considerable portion of the joint zone shear can be resisted by diagonal strut action $2,3,4$. In the elastic condition the majority of the flexural compression forces are resisted by the concrete, and the bond conditions in the compressed corner of the joint are good. This disposition of forces enables the action to contribute to the shear strength. However, the situation changes if the beams undergo plastic hinging against the joint zone for two reasons described below.

(1) The hinging of the beams causes the tension reinforcement to yield and wide cracks form. When this tension zone is subsequently subjected to compression the steel has to be yielded back in compression before the cracks can be closed and an appreciable compression force can be carried by the concrete. Consequently the flexural compression force in the concrete $\mathrm{C}_{\mathrm{cl}}$ decreases, and the shear resisted by diagonal strut action is reduced to the value which can be sustained by the greatly reduced concrete force and the bond force between the beam reinforcement and the concrete in the compressed corner of the joint $\Delta \mathrm{T}_{\text {beam }}$.

(2) With diagonal strut action the flexural tension forces are constant through the joint, and they are anchored on its far side. Under the action of flexure in the beams the reinforcement is always subjected to tension. Thus any extension of the yielding of the beam steel into the joint causes the bars in this zone to increase in length. As there can be no corresponding extension of the concrete, the reinforcement must slip through the joint zone as the load is reversed, unless the joint zone shear can be resisted by another means such as panel truss action. If panel truss action is not available the resulting slip destroys bond, and each load reversal causes the flexural reinforcement anchorage location to move progressively further into the column or beams beyond the column. The slipping of the bars initially reduces the stiffness of the joint. However, after a number of load cycles the repeated opening and closing of wide cracks reduces the resistance of the 


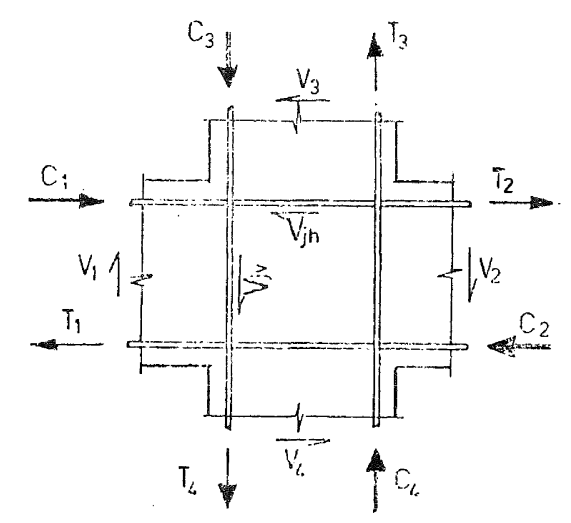

Fig. 1 Forces Acting on an Interior Joint

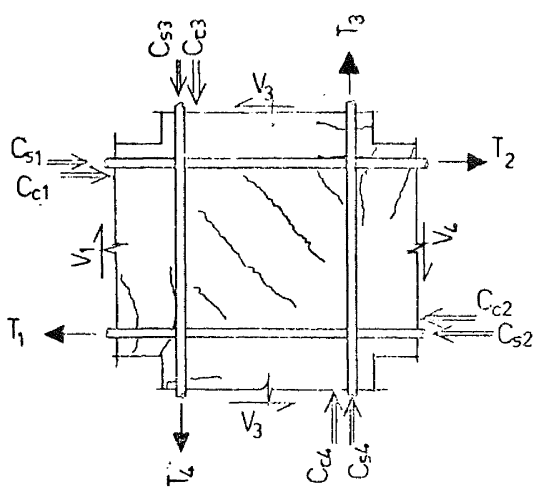

Crack Pattern and Forces on Joint

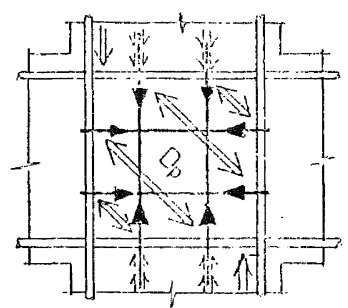

Panel Truss Action

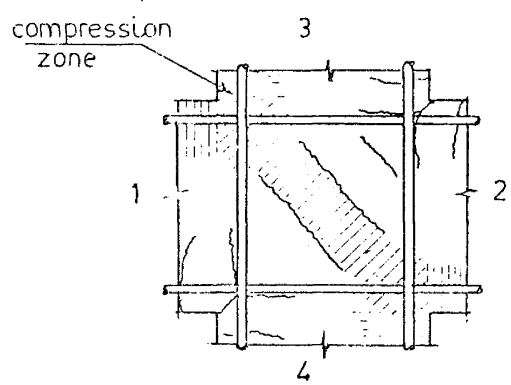

Compression Zone for Diagonal Strut Action

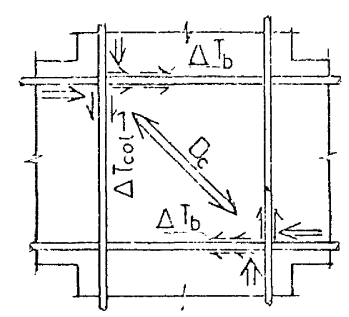

Diagonal Strut Action

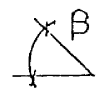

$A_{h s}$ - area joint zone ties

$A_{v s}$ - area joint zone vertical reinforcenien

b - subscript - bean

$\operatorname{col}$ - " - column

c - " - concrete

C - compression force

D - diagonal compression force

$f_{s}$ - stress in reinforcement

$\rho$ - subseript - pane] truss action

$s \quad-\quad-$ steel

$\Delta \mathrm{C}_{\mathrm{c}_{3}}-$ part of $\mathrm{C}_{\mathrm{c} 3}$

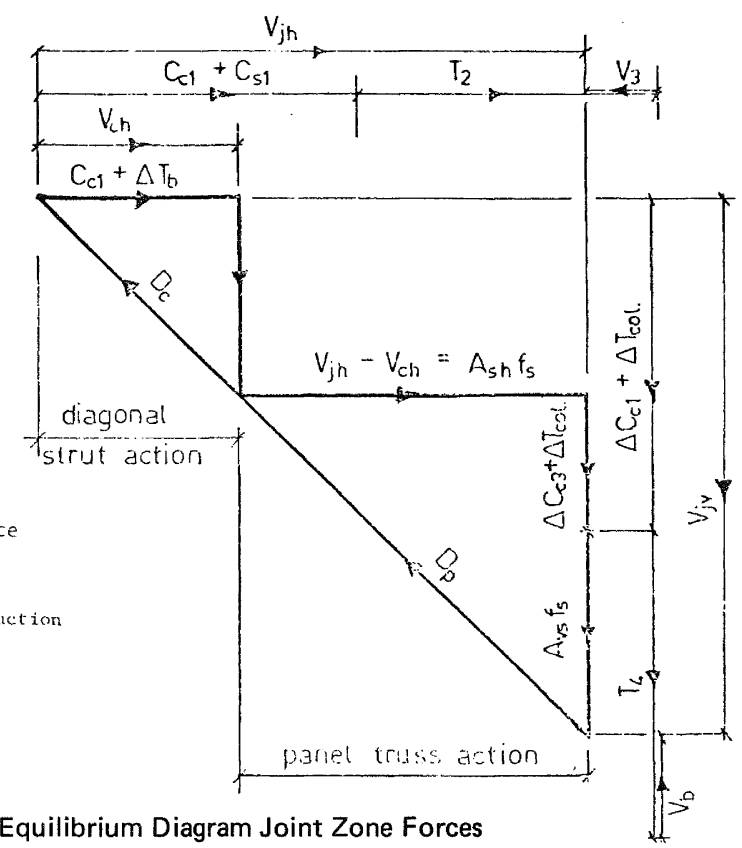

Fig. 2 Joint Zone Forces Associated with Diagonal Strut and Panel Truss Actions 
concrete to the diagonal compressive stresses and complete failure can occur.

As previously noted the degradation of diagonal strut action occurs due to the yielding of the flexural beam reinforcement and the loss of bond resistance in the compression corners of the joint. If these two actions can be prevented diagonal strut action becomes a viable means of resisting joint zone shear, as has been demonstrated by tests ${ }^{3}, 4$.

Panel truss action is illustrated in Fig. 2. This mechanism of shear resistance requires a set of adequately anchored vertical and horizontal bars in the joint. The horizontal shear force resisted by this action may be taken as the total joint zone shear minus that resisted by diagonal strut action, and it is introduced into the beam by bond forces acting between the beam flexural

reinforcement and the concrete in the joint. By considering the equilibrium requirements for the joint in the horizontal direction the amount of horizontal shear reinforcement may be found. With reference to figure 2 . assuming the total area of joint zone stirrups of "A $s h$ " is at yield $\mathrm{f}_{\mathrm{y}}$ " equilibrium requirements give -

$$
A_{s h} f_{y}=V_{j h}-V_{c h}
$$

where $V_{\text {ch }}$ is the shear resisted by diagonal strut action.

In a beam column joint in which plastic hinges form against the column faces diagonal strut action initially resists a considerable portion of the joint shear. However, as the number of load reversals increases this mechanism of resistance sustains less shear, and panel truss action picks up an increasing portion of the load if the required joint zone reinforcement is in place. In columns with axial loads of less than 0.1 $A_{\mathrm{f}^{\prime}} \mathrm{C}^{\prime}$, and where the flexural reinforcement in the beams yields where it enters the joint, $V_{c h}$ is taken as zero for the purposes of design. 1

A similar expression to equation 2 may be derived for the joint zone reinforcement required by considering vertical equilibrium. With reference to Fig. 2 , and by assuming the area of vertical joint reinforcement $A_{s v}$ is acting at a yield stress $f_{y} \quad s v$ equilibrium requires give

$$
A_{s v} f_{y}=V_{j v}-V_{c v}
$$

where

$$
\mathrm{V}_{\mathrm{cV}}=\mathrm{C}_{\mathrm{c} 3}+\Delta \mathrm{T}_{\mathrm{col}} .
$$

in which $\mathrm{C}_{\mathrm{C} 3}$ is the concrete compression force in the column due to flexure and axial load, and $\Delta \mathrm{T}_{\mathrm{col}}$ is the bond force which can be transmitted from the column flexural reinforcement to the concrete in the compressed corner of the joint. usually designed to be stronger than the beam, and consequently yield of the column flexural reinforcement should not occur to any appreciable extent, so that both the concrete compression force $\mathrm{C}_{\mathrm{c} 3}$ and the bond force $\Delta \mathrm{T}_{\mathrm{col}}$ can be sustained. Hence, in the weak beam strong column situation the vertical reinforcement requirements for shear reinforcement in the joint are only about half of that required for horizontal shear.

\section{BOND PLATE JOINTS:}

In a previous paper ${ }^{3}$ the concept of the bond plate joint was described and illustrated by comparative tests. The beam and column flexural reinforcement was anchored on each side of the joint by the use of bond plates. Under cyclic loading plastic hinges were designed to form in the beams close to the column forces, but the migration of the yield zone into the joint was prevented by welding additional small diameter bars to the beam flexural reinforcement between the bond plates. The joint zone designed on this basis behaved exceptionally well. However, the reinforcement arrangement was not practical due to the difficulty of threading beam bars with bond plates through a column reinforcement which also contained bond plates.

The practical difficulty associated with placing the reinforcement is greatly reduced if the bond plates can be omitted from the column reinforcement. A review of test results from a number of beam column joint tests showed that high bond stress levels of the order of 10 to $12 \mathrm{MPa}$ could be sustained over part of the joint under cyclic load conditions provided that the reinforcement did not yield. With this information it appeared possible to rely on bond to anchor the column bars through the joint, and to use bond plates only on the beam reinforcement. In the test of unit 1 of reference 3 it was found that average bond stresses in the column bars of over $5 \mathrm{MPa}$ were sustained through the joint under cyclic conditions. This high level of bond stress was sustained without any evidence of slip of the column bars in spite of the poor overall performance of the joint and excessive spalling at an early stage of the test. Average bond stress levels of the order of $4 \mathrm{MPa}$ were sustained in beam column joints tested by Beckingsale 7 .

To test the performance of a bond plate joint in which the column bars were anchored by bond, two units were built. The column reinforcement was chosen so that the average bond stresses in the bars did not exceed $5 \mathrm{MPa}$.

\section{DETAILS OF UNIT 1:}

The details of the reinforcement in the first unit are shown in Fig. 3. The horizontal joint shear reinforcement consisted of four sets of $10 \mathrm{~mm}$ stirrups, each set having four legs. In addition there were four $6 \mathrm{~mm}$ ties placed round the intermediate column bars. The quantity of shear reinforcement provided was approximately one third of that required for a standard joint and just under the area required for an elastic joint designed according to the draft NZS code ${ }^{1}$. Each 


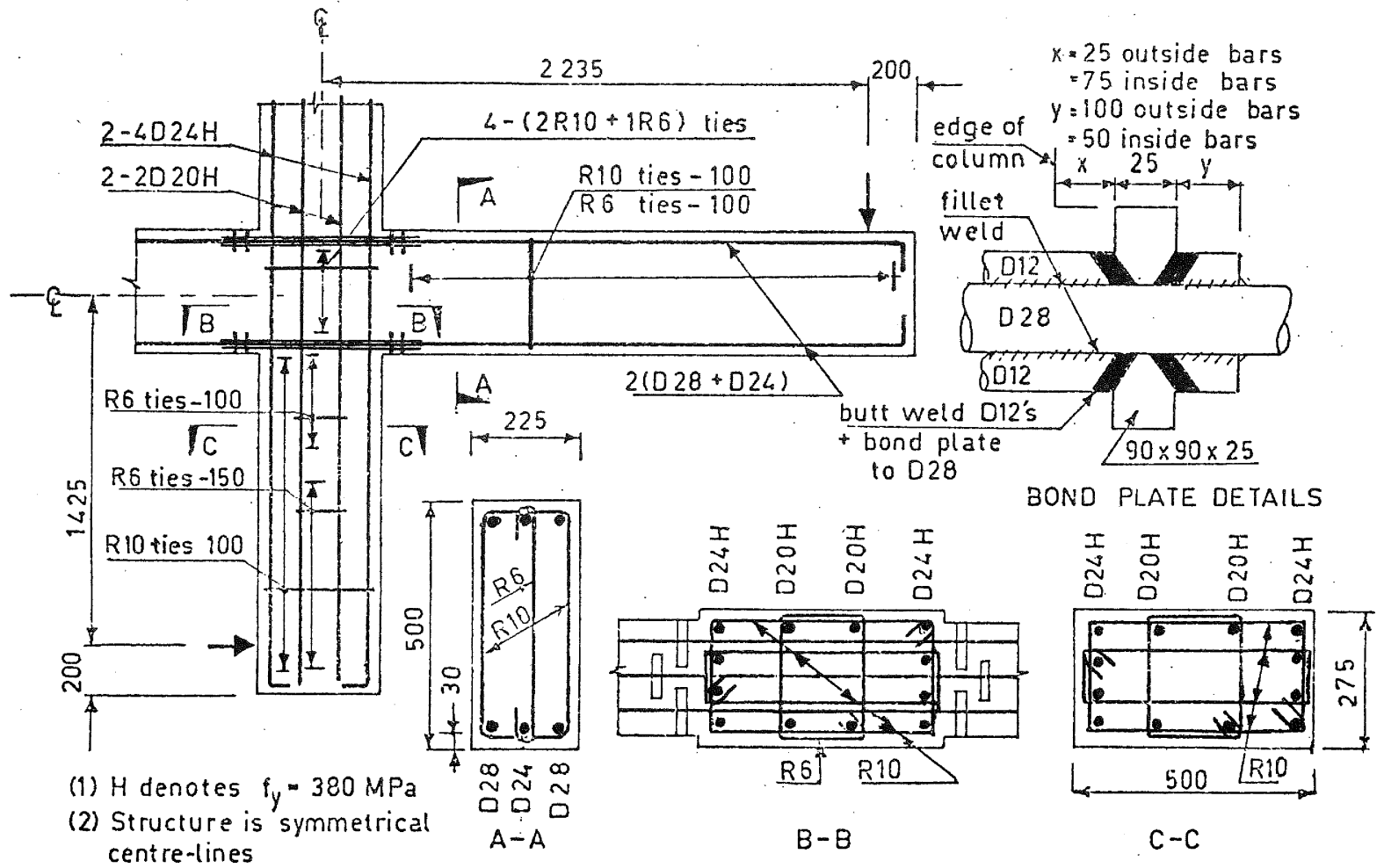

Fig. 3 Reinforcement Details of Unit 1

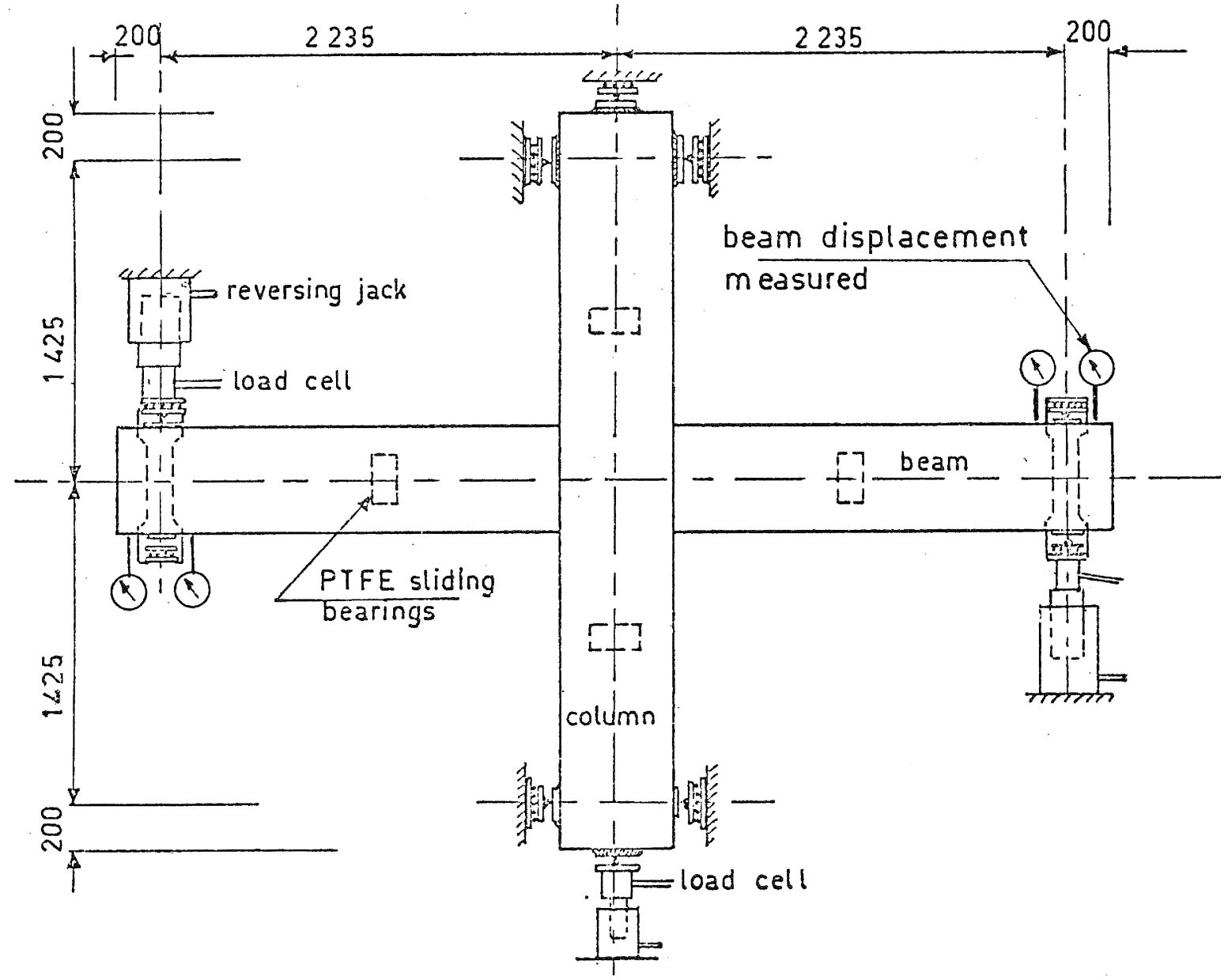

Fig. 4 Method of Applying Loads to Beam Column Units 
bond plate was proportioned to anchor, by bearing against the concrete, the load generated by the tension yield of the bar on the far side of the joint together with the compression yield of the bar on the near side of the joint. Under this loading the bearing stresses were limited to $1.6 \mathrm{f}_{\mathrm{c}} \cdot$ As no crushing occurred during the tests it was concluded that this stress level was acceptable. The four intermediate column bars in the unit provided the vertical shear reinforcement. The area of this steel was in excess of that required by the draft NZS code ${ }^{2}$

In an attempt to prevent the yield penetration of the beam reinforcement into the joint, two additional $12 \mathrm{~mm}$ bars were fillet welded to each main bar of beam flexural reinforcement in the joint zone. These $12 \mathrm{~mm}$ bars were butt welded to the bond plates and a $50 \mathrm{~mm}$ extension of each bar was placed beyond the bond plate with the intention of preventing the yield zone from reaching the heavy bond plate welds (see Fig. 3).

The concrete was purchased from a local ready mix plant, and its cylinder strength, measured during the test, was $30 \mathrm{MPa}$. The reinforcement was supplied ready bent by a local distributor, and tests made on the main reinforcing bars gave a yield stress of $300 \mathrm{MPa}$ for the beam reinforcement and $423 \mathrm{MPa}$ for the column reinforcement.

\section{TEST ARRANGEMENT FOR UNIT 1:}

The method of applying the loads to the beam column unit is shown in Fig. 4. It was supported on the floor in a horizontal position by four PTFE sliding bearings. The test frames were bolted to the strong floor round the unit, and the load was applied by hydraulic jacks powered by a hand pump for the beam loads, and a motorised pump for the axial load. The axial load level was adjusted at frequent

intervals during the test in an attempt to maintain it at $125 \mathrm{kN}$. However, the measured load varied from 100 to $150 \mathrm{kN}$. The loads acting on the beams were applied by reversing jacks acting through coupled load cells. The arrangement was such that only normal forces could be transmitted to the beams, and no restraint was provided to any change in length.

The loading sequence followed in the test of unit one is shown in Fig. 5. It commenced with two elastic load cycles in which a load equal to three quarters of the calculated ultimate value was applied sequentially in each direction. The measured load deflection points were plotted, and by linear extrapolation the deflection at ultimate load was found. This displacement was taken as the ductility one, or D1, displacement. From this stage the displacements shown in Fig. 5 were applied to the beam. The subsequent loading history consisted of applying two cycles each in which displacements of twice, four times and six times the DI displacement were applied to the beams. These are referred to as the D2, D4 and D6 displacements respectively.

\section{TEST RESULTS FOR UNIT 1:}

The results of the tests are only briefly described below. Further details of these together with information on the instrumentation is given in reference 6 .

The average load deflection curve for the load points on the two beams is shown in Fig. 6. The performance of the unit up to the end of the first D4 cycle was acceptable. However, in subsequent load cycles appreciable strength and stiffness degradation occurred, and significant shear pinching was evident. This was due to a deterioration of the joint zone which clearly did not perform in an acceptable manner. It was necessary to look closely at the experimental results from this test to understand the reason for the premature failure.

In the joint zone of this unit the area of the beam flexural reinforcement was locally increased by approximately $40 \%$ by welding the two $12 \mathrm{~mm}$ bars to each bar of flexural reinforcement. These bars were welded directly above and below the main steel as shown in Fig. 3. In spite of this increased area of reinforcement, strain gauges mounted on the reinforcement between the bond plates showed that yield in tension occurred in the D4 cycles. This action caused the bars to elongate. Consequently the bars slipped through the joint to allow the plates to come into contact with the concrete when the load was reversed. At first it was thought that the action of welding the $12 \mathrm{~mm}$ bars to the main steel might have affected the steel properties, or that a weld failure had occurred. However, these possibilities were eliminated by cutting a composite $28 \mathrm{~mm}-12 \mathrm{~mm}$ bar out of the joint and subjecting it to an axial tension test. It was found that the reinforcement between the bond plates in this test yielded at a load of close to 125\% of the yield load of the bar by itself, indicating that there had been no appreciable degradation due to welding or a welding failure.

A number of stirrup strains were measured during the test by mechanical strain gauges acting on studs welded to the stirrups. Extensive yielding appeared to occur in the D4 cycle. This coincided with a marked increase in the measured shear deformation of the joint zone as shown in Fig. 7. The shear distortion of this zone was appreciable even in the elastic load cycles, but it reached $10 \times 10^{-3}$ radians at the end of the $D 4$ cycles and $40 \times 10^{-3}$ radians in the D6 cycles.

From these results it was apparent that the yielding of the beam flexural reinforcement between the bond plates was due to the local bending of the composite bars caused by the shear deformation of the joint zone (see Fig. 7). The additional $12 \mathrm{~mm}$ bars were welded above and below of main reinforcing bars which gave a steel section with a total depth of $56 \mathrm{~mm}$. The bending of this composite bar about its strong axis together with the high axial tension appears to have been sufficient to lead to the yield of this reinforcement and the 


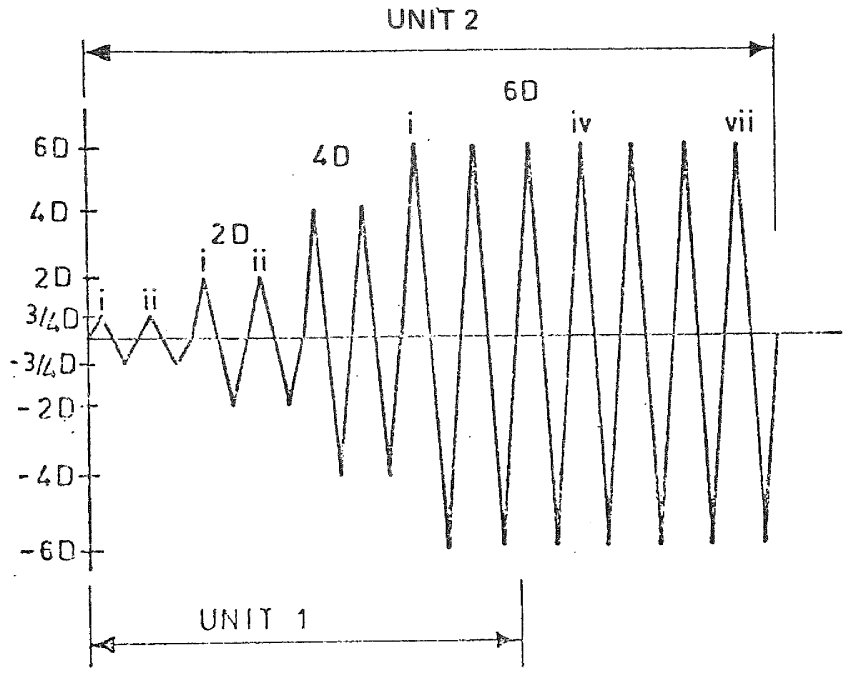

Fig. 5 Loading Sequence Applied to Units

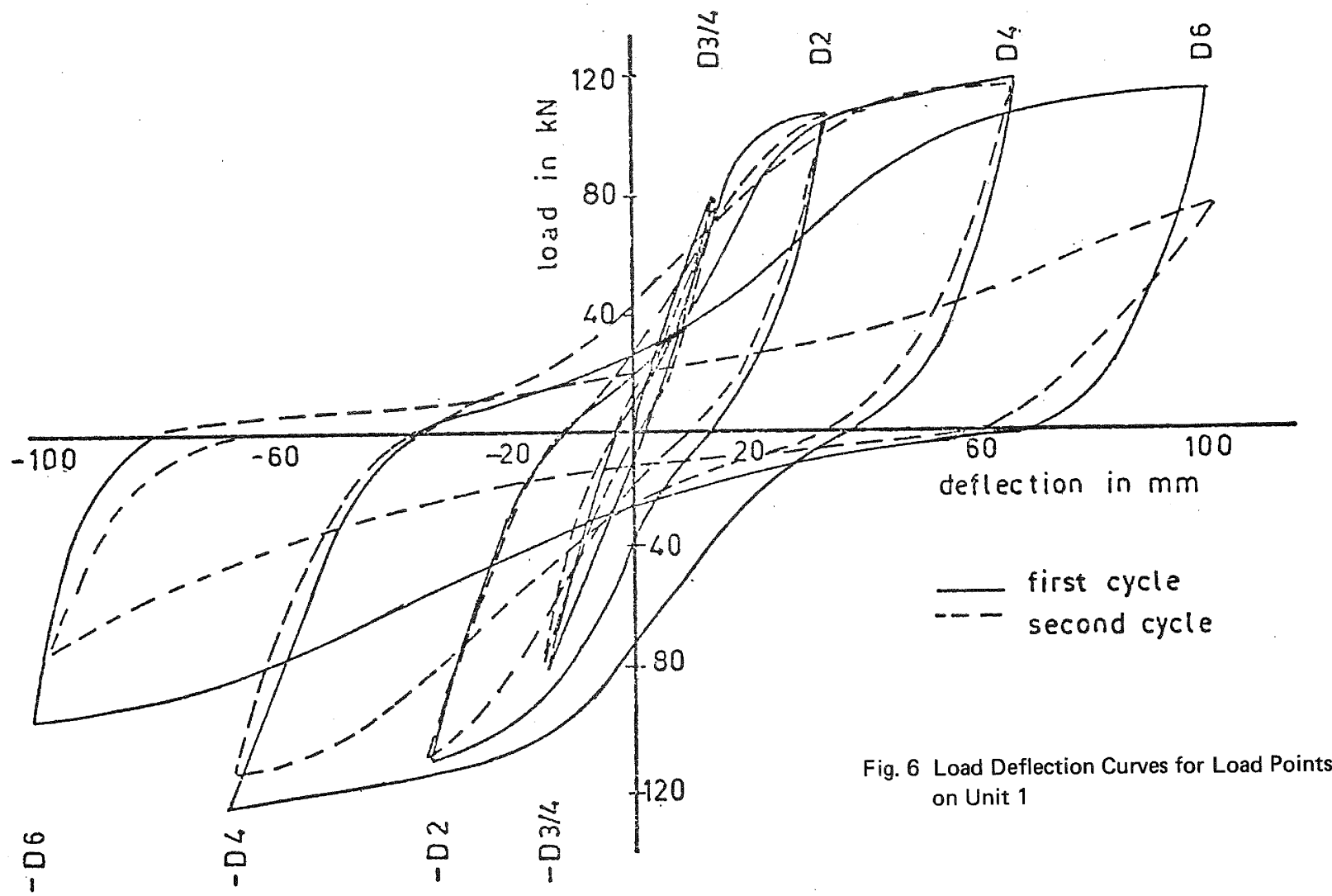



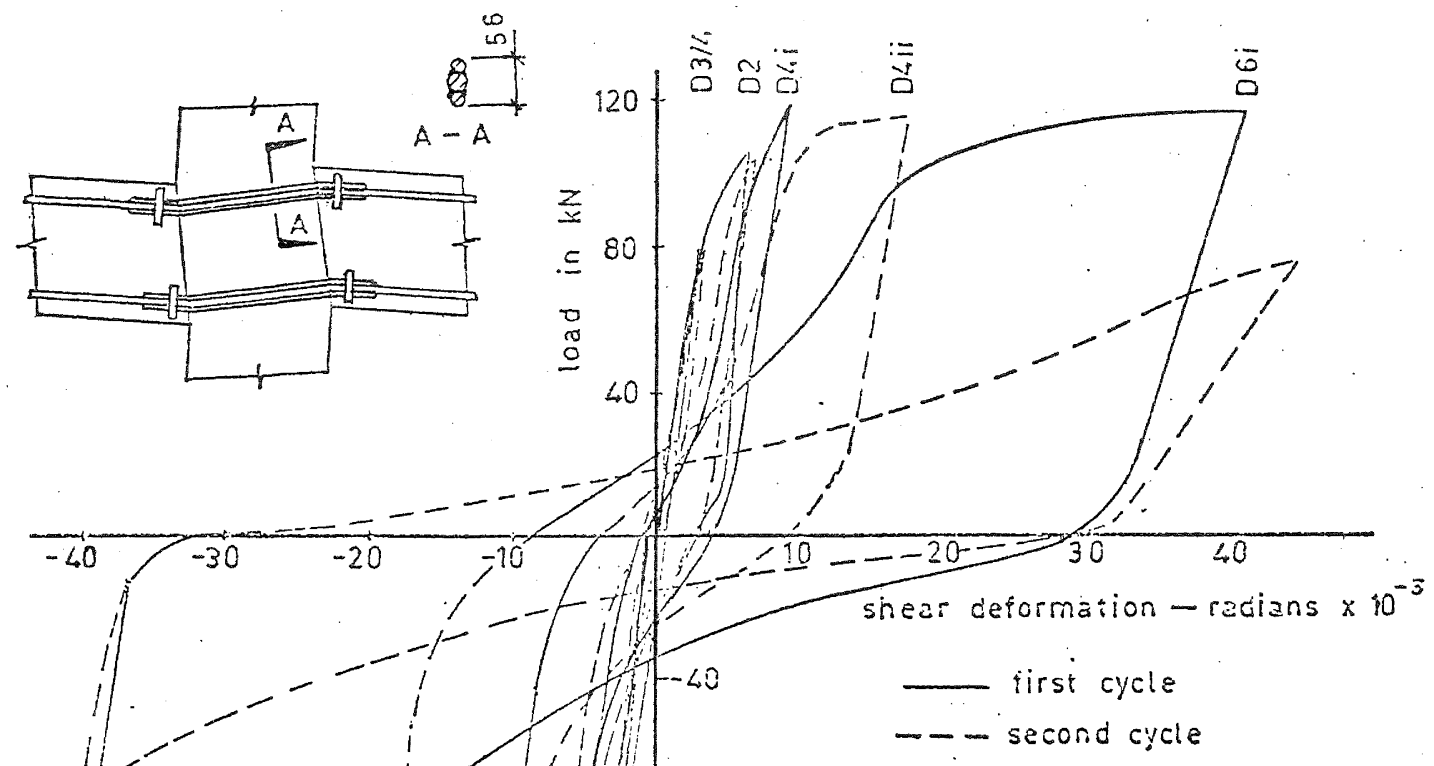

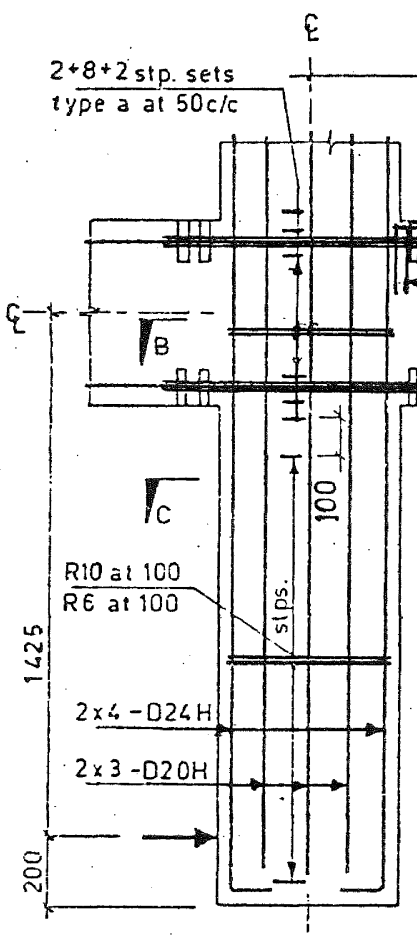

(1) $\mathrm{H}$ denotes $f y-380 \mathrm{MPa}$

(2) $D=$ deformed $R=$ round

(3) structure symmetrical about $E$ 's
2235

$\frac{1}{0} \underset{0}{0} \frac{i}{0}$

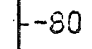

$-120$
Fig. 7 Shear Deformation of Joint Zone in Unit 1 $x=25$ inside bars

- 75 outside bars

$y=70$ outside bars

- 120 inside bars

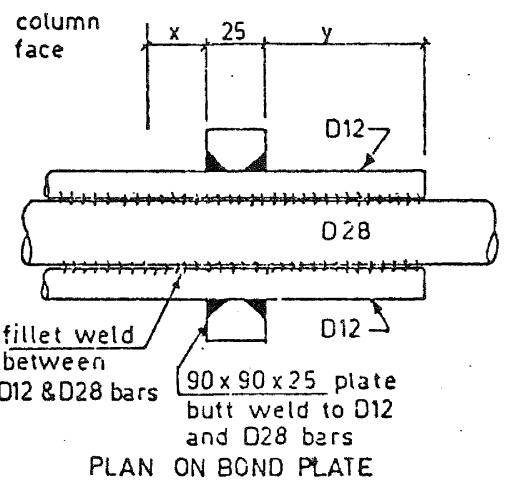

PLAN ON BOND PLATE

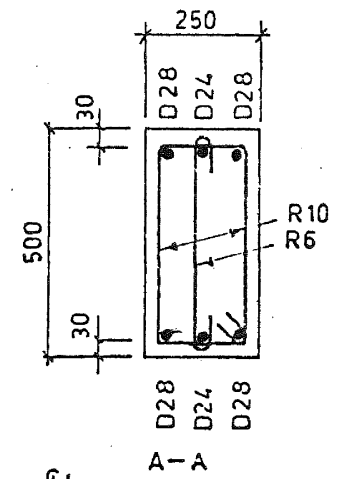

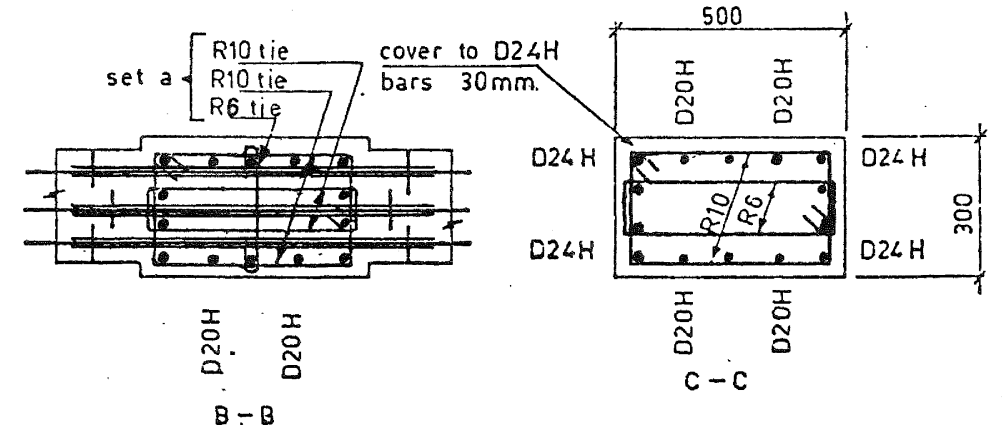

Fig. 8 Reinforcement Details for Unit 2 


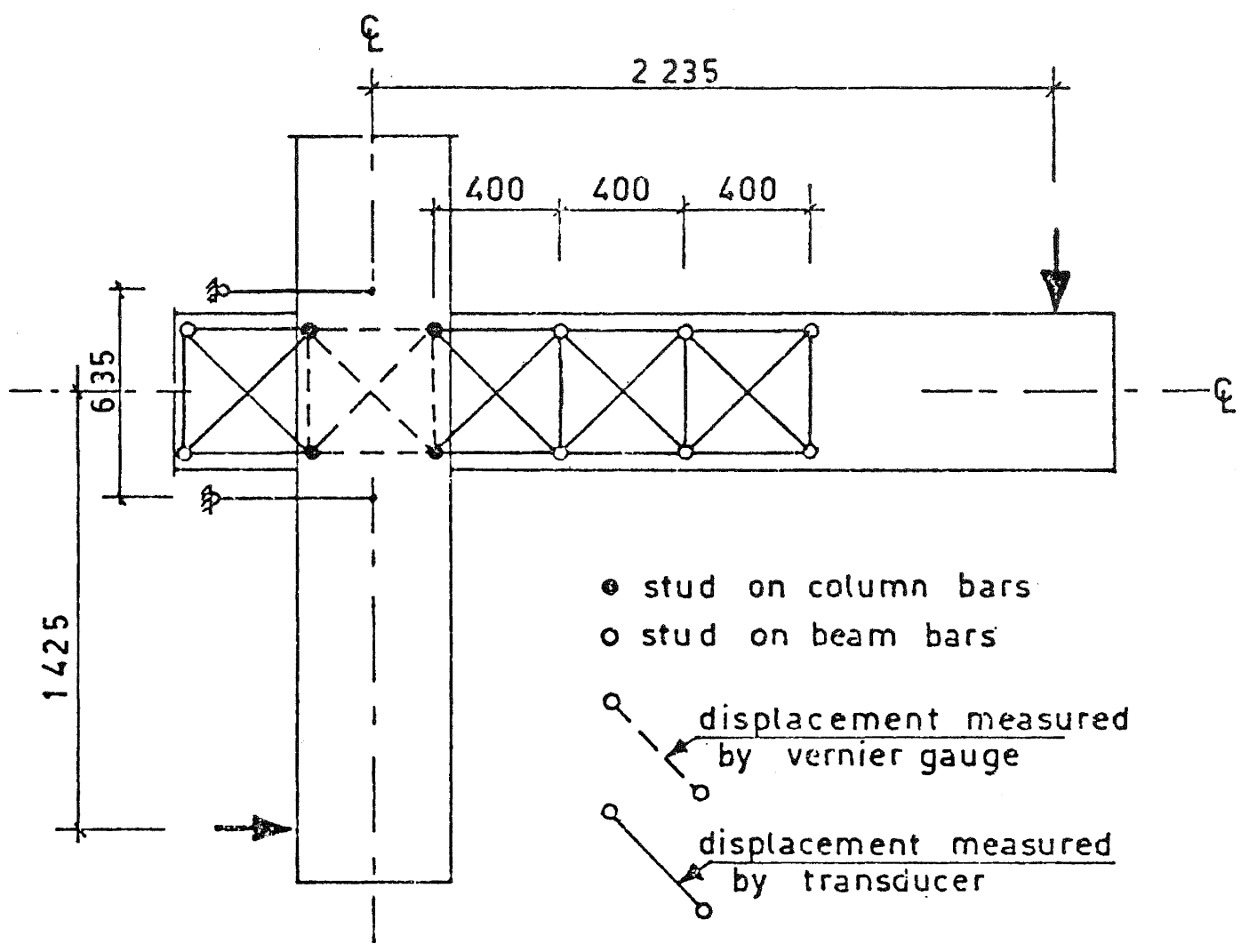

LOCATION OF DISPLACEMENT TRANSDUCERS

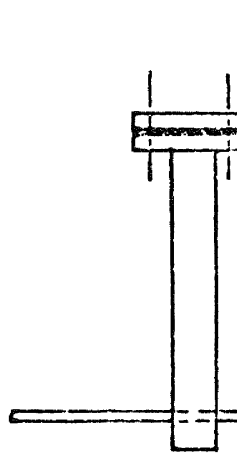

strain gauge

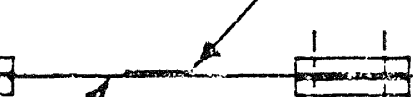

spring steel

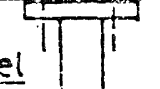

grease tape and plastic tube removed to

leave gap

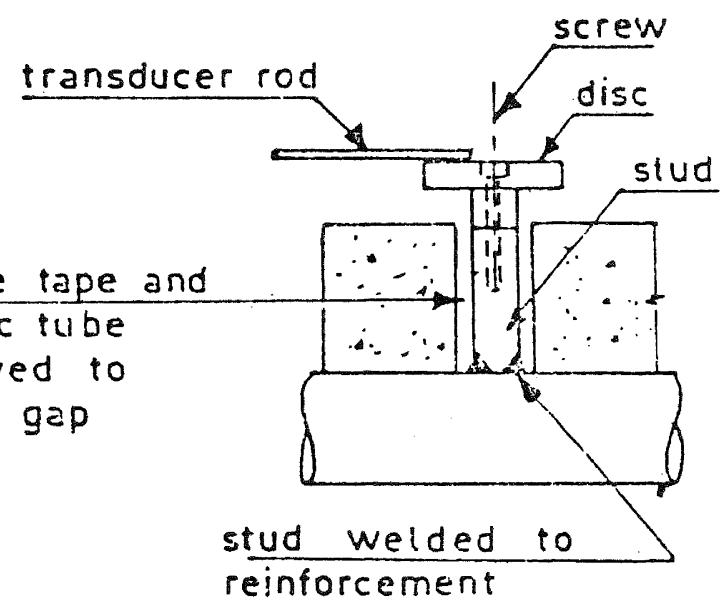

rod atiached to

discs on studs

STUDS ON REINFORCEMENT

DISPLACEMENT TRANSDUCER

Fig. 9 Displacement Measurements on Unit 2 
subsequent degradation of the joint zone.

To prevent the same defect from occurring in unit two a number of the details were changed.

\section{DETAILS OF UNIT TWO:}

There were two possible ways of improving the joint zone detailing, namely stiffening the zone by adding additional stirrups, and rearranging the composite bars so that the shear kinking would bend these about their weak axis. In unit two both these ideas were incorporated.

The reinforcement details for this unit are shown in Fig. 8. They are similar to those in unit one, but with the changes noted below.

The joint zone ties were increased from four to eight sets.

The additional $12 \mathrm{~mm}$ bars were welded to the sides of the main beam bars in the joint zone. To accommodate this steel it was necessary to increase the beam width from $200 \mathrm{~mm}$ to $250 \mathrm{~mm}$ and the column width from $250 \mathrm{~mm}$ to $300 \mathrm{~mm}$.

(3) An additional intermediate column bar was used, but the $6 \mathrm{~mm}$ column ties were omitted.

As in the first unit the reinforcement was supplied "pre-bent" by a local supplier. The yield strength of the beam reinforcement was 278 MPs, and of the column reinforcement $409 \mathrm{MPa}$. The ready mixed concrete cylinder strength was measured as $36.2 \mathrm{MPa}$.

The method of testing was similar to that used in Unit one, though the instrumentation had improved and this allowed more data to be collected from the test. The control of the axial load was more sensitive, and in this unit it did not change by more than + or $-5 \mathrm{kN}$ from the intended level of $125 \mathrm{kN}$. The loading sequence was the same as for unit one except that a further five D6 cycles were applied. In this test numerous displacement measurements were made with a mechanical Vernier gauge and with electrical resistence displacement transducers. These measurements enabled the different components of displacement in the unit to be evaluated, see Fig. 9.

\section{RESULTS OF UNIT TWO:}

The column and joint zone of this unit performed exceptionally well. The maximum crack width recorded on the joint at any stage of the test was $0.9 \mathrm{~mm}$, and when the load was removed all the cracks closed indicating that the joint and the column remained elastic.

The averaged load deflection curve for the load points on the beams is shown in Fig. 10. Pinching of the loop is apparent for the third D6 and subsequent cycles. The displacement measurements made on the unit indicated that this was due to the development of shear deform- ation in the beams. This component was calculated, and the results are plotted in Fig. 11. The form of the shear deformation versus shear curve is similar to that obtained in other tests. 8 After a few inelastic load cycles appreciable shear deformation develops. The shear stiffness is low at low load levels. This could be expected to have a very marked influence on the dynamic performance of structures subjected to the small amplitude vibrations during seismic attack.

The transverse measurements made in the plastic hinge zones of the beams showed that extensive tension yield occurred in the beam stirrups in spite of the generous provision of shear reinforcement in the unit. At the end of the D4 cycles the yield extension was of the order of $2 \frac{1}{2} \mathrm{~mm}$, and this increased to $4 \mathrm{~mm}$ in one beam and $8 \mathrm{~mm}$ in the other beam at the end of the second D6 cycle. This yield occurred in spite of the provision of shear reinforcement to carry 170 per cent of the maximum shear applied to the beams.

The mechanism of shear resistance in hinge zones of beams is somewhat different from that in a normal concrete member, and the familiar design equations no longer apply. In particular the critical diagonal crack inclinations change to enable the flexural rotations to occur by rotation in the diagonal cracks, while at the same time the shear is carried by the stirrups crossing the cracks. The mechanism of shear resistance and deformation in plastic hinge zones of concrete beams will be the subject of a subsequent paper.

The deflection of the load points was due to deformation caused by the following:

(i) flexural deformation of the column,

(ii) deformation in the beam column joint,

(iii) flexural deformation of the beam and,

(iv) shear deformation in the beam.

The instrumentation on the unit enabled the displacement of each of these components to be determined separately. These values are compared in Fig. 12 with the measured values at the peak ductility displacements. The importance of shear deformation in the beams on the overall behaviour of this unit is apparent from this figure. It may be noted that in the last five D6 cycles the beam shear deformation accounted for more than 37 per cent of the total deformation.

As in unit one strain measurements were made with mechanical strain gauges on some of the stirrups in the joint zone region. The yield strain appears to have been reached in one of the stirrups at the second D6 cycle, though this strain level dropped in subsequent cycles, presumably due to the strength degradation of the unit as a whole. By considering the average apparent strain in the stirrups it was concluded that the area of horizontal joint zone reinforcement could 


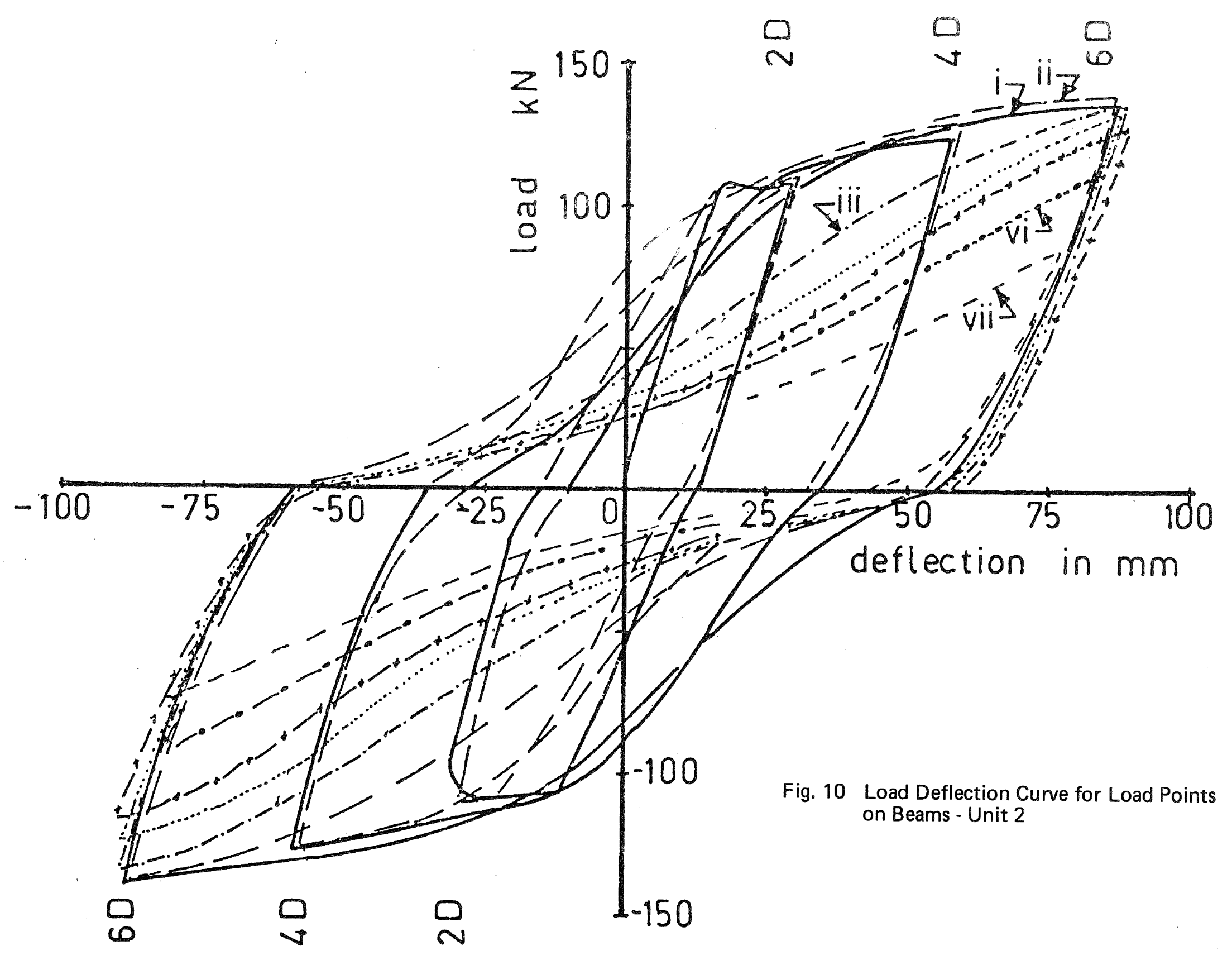




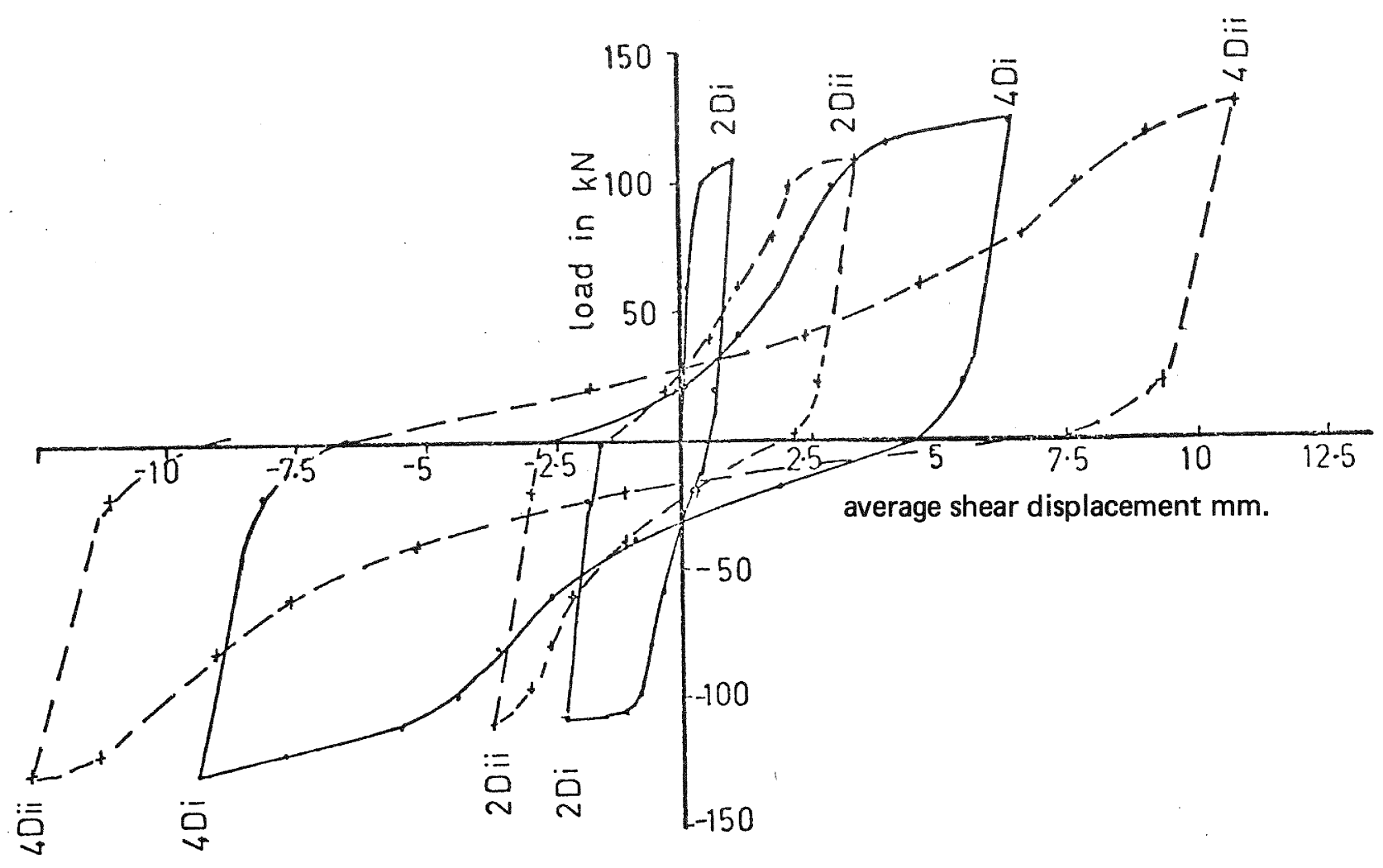

Shear Displacements to and of D4 Cycles

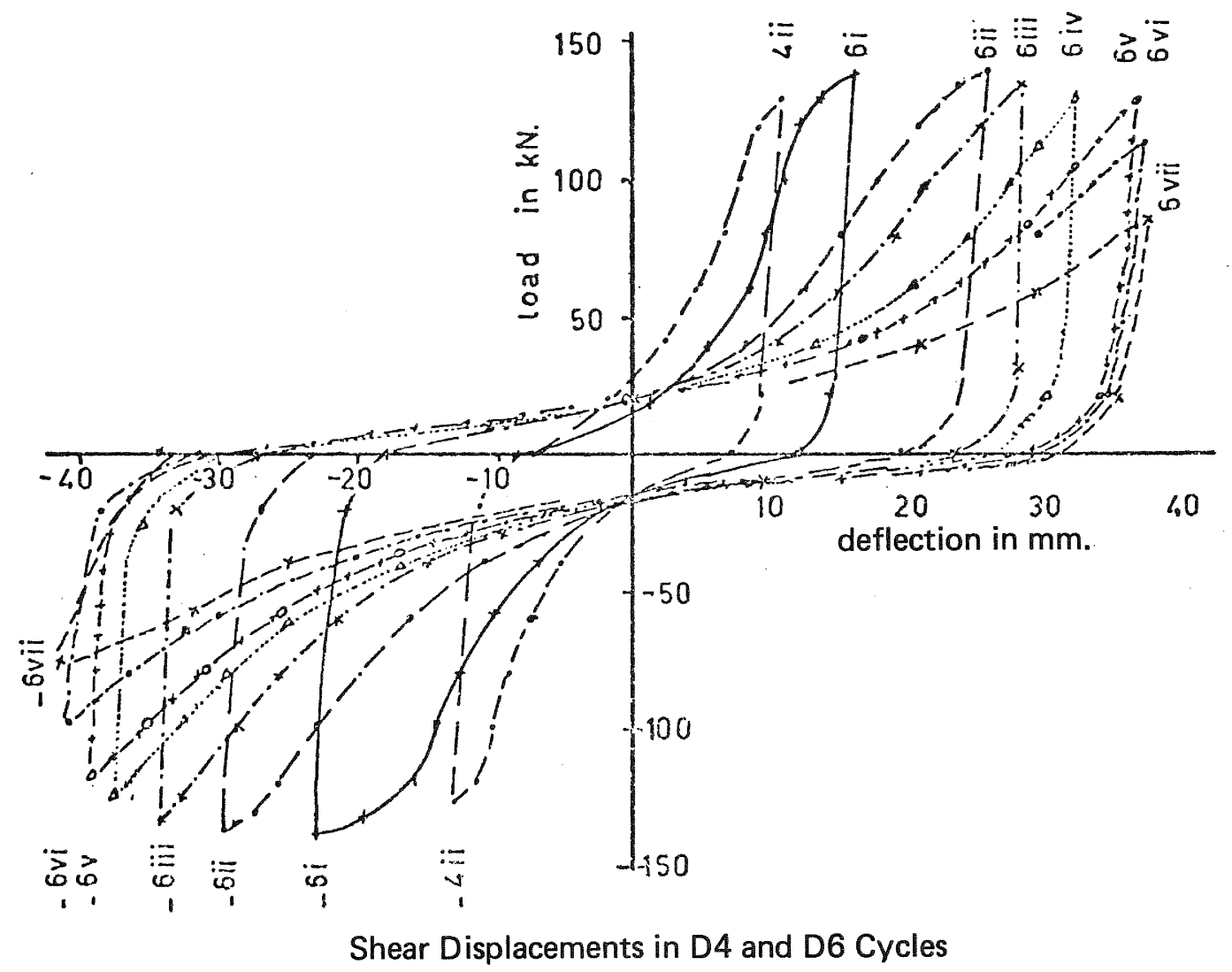

Fig. 11 Shear Displacements in Beams of Unit 2 
have been reduced to three quarters of that provided without the danger of inducing extensive yield of these stirrups. This reduced area of reinforcement corresponds closely to that required by the draft code for elastic joints (see appendix 1).

Mechanical strain gauges were used to measure strains on the intermediate column bars. The recorded stress levels were well below the yield level. If it is assumed the bar forces would remain constant as the area is reduced, the intermediate column bar area could have been changed from $1885 \mathrm{~mm}^{2}$ to $1350 \mathrm{~mm}^{2}$ before the stress level of $380 \mathrm{MPa}$ was reached in the most critically stressed bar. the total force carried by these bars could be redistributed amongst themselves so that all the bars were operating at yield, the required area could have been reduced to $750 \mathrm{~mm}^{2}$. The draft code requires an area of $1108 \mathrm{~mm}^{2}$, which is midway between the upper and lower limits suggested by the experimental measurements.

\section{CONCLUSIONS:}

(1) By welding small diameter bars on the sides of beam flexural reinforcement where it passes through a joint, and by welding bond plates to the main beam flexural reinforcement on each side of the joint, it is possible to keep the joint zone elastic under the action of cyclic hinging of beams on each side of the column.

(2) Some of the potential advantages of using a bond plate joint instead of one of the more standard details are noted below.

(i) The damage zone under seismic conditions is located in the beams where it is accessible for repair.

(ii) The joint zone remains elastic, so that the amount of joint zone reinforcement may be reduced, enabling smaller beams with higher steel percentages to be used.

(iii) With the bond plates, bond stresses through the joint zone are no longer critical, and consequently the limitations on column and beam bar sizes no longer apply. Larger diameter bars with simpler steel arrangements may be used in the beams, and column sizes in buildings with a few floors may in some situations be reduced in size.

(iv) With the reduced beam and column dimensions the structural flexibility increases. In low rise structures this can lead to a reduction in the design lateral load for earthquake resistance.

(3) Disadvantages of the bond plate joint arise from the welding and fabrication costs involved in adding the bond plates and the additional small diameter bars in the joint zone, and from the reduced flexibility in placing the flexural reinforcement through the column bars.

(4) A number of tentative recommendations may be made regarding the design of bond plate joints:

(i) The bond plates should be located in the beams close to the column face. Each plate should be designed to transmit the sum of the compression and tension forces carried by the bar on each side of the joint at a concrete bearing stress not exceeding $1.5 \mathrm{f}$ ' at yield of the reinforcement.

(ii) The yielding of the reinforcement at and between the bond plates must be prevented. This may be achieved by welding small diameter bars to the sides of the main flexural reinforcement passing through the joint so that these bars extend a minimum distance of $2 \frac{1}{2}$ main bar diameters beyond the bond plates on each side of the joint. The area of these additional bars should be sufficient to prevent yield of this zone with a margin of 15 per cent above the strain hardened strength of the beam reinforcement. This margin is to allow for the adverse effects of locked-in welding stresses and local bar bending due to joint shear deformation.

(iii) Joint zone shear reinforcement in the form of ties and intermediate column bars should be provided to control crack widths and provide adequate joint zone stiffness.

The requirements of the draft codel for elastic joints appears to be adequate for this purpose.

(iv) Bond plates are not required on the column flexural reinforcement provided bond stresses are not excessive. The results of these and other tests indicate that average bond stresses through the joint of up to $5 \mathrm{MPa}$ are acceptable on non-yielding column bars. 


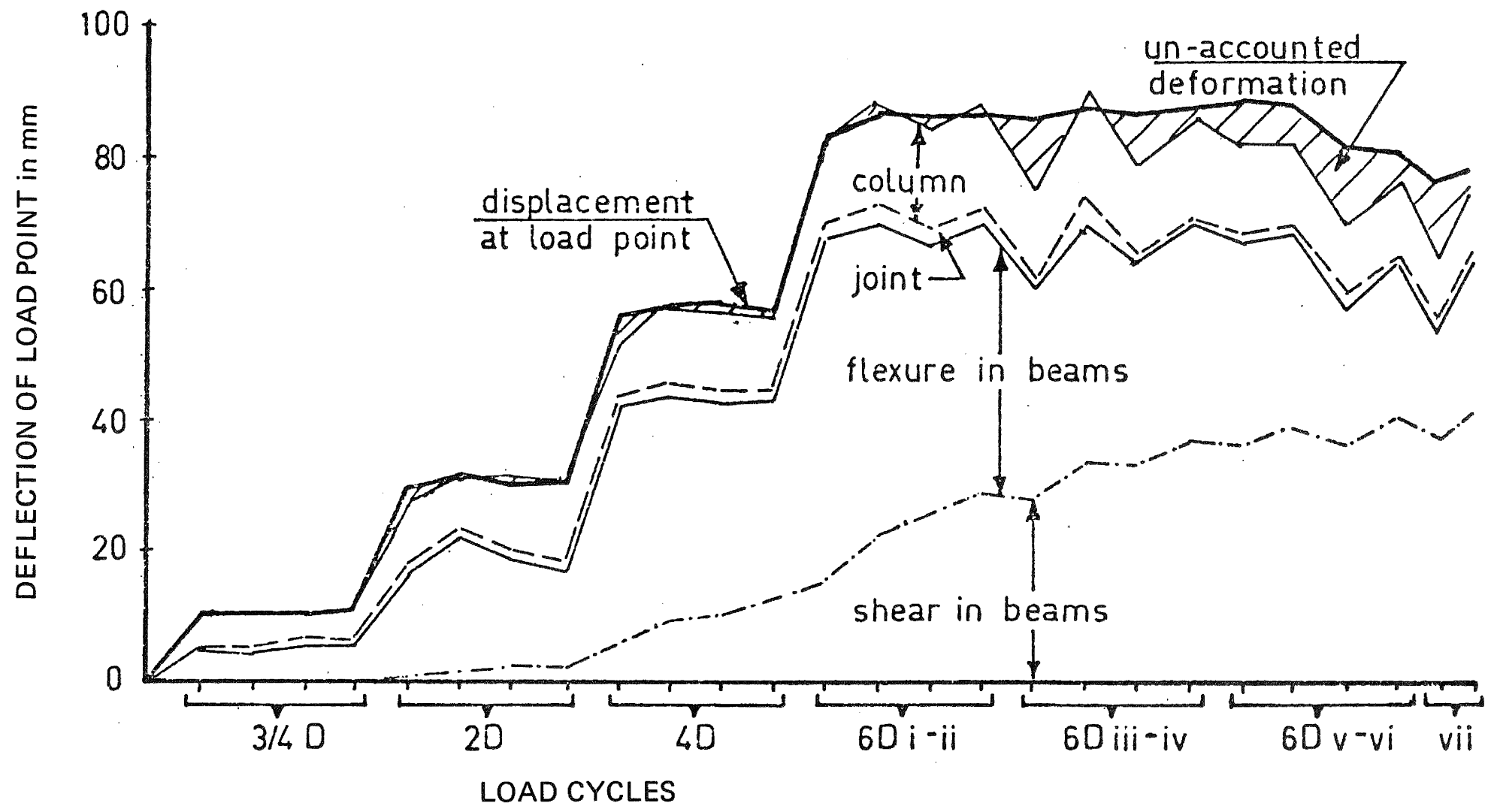

Fig. 12 Displacement Components in Unit 2 at Peak Ductilities 
(5) Shear deformation of the beams was of major importance in the later stage of the test. The low shear stiffness of beams at low load levels can be expected to have a significant influence on the dynamic performance of reinforced concrete structures under severe seismic conditions.

\section{ACKNOWLEDGEMENTS :}

The first beam column unit reported in this paper was tested by Mr T.H. Nguyen as part of an M.E. project.

The assistance of Mr G.W. Blanchard of the Mechanical Engineering Department for writing the paper tape reading routine used to reduce the experimental results is gratefully acknowledged.

Financial assistance for these tests was provided by the University Grants Committee and the Ministry of Works and Development.

\section{REFERENCES :}

(I) SANZ, DZ 3101 "Draft NZ Standard for the Design of Concrete Structures", November 1980 .

Paulay, T., Park, R. and Priestley, M.J.N. "Reinforced Concrete Beam Column Joints under Seismic Actions", Proceedings ACI., Nov. 1978, No. 11, Vol. 75.

(3) Fenwick, R.C., and Irvine, H.M., "Reinforced Concrete Beam - Column Joints for Seismic Loading", Bulletin of N.Z. National Society for Earthquake Engineering, Pt. 1 Sept. 77, No. 3, Vol. 10, Part 2, December 77, No. 4, Vol. 10.

(4) Birss, G.R. 'The Elastic Behaviour of Earthquake Resistant Reinforced Concrete Interior Beam-Column Joints" Research Report 78-13, University of Canterbury, Ch. Ch.

(5) Taylor, H.P.J., and Clark, J.L., "Some Detailing Problems in Concrete Frame Structures", The Structural Engineer, Jan. 76, No. 1, Vol. 54 .

(6) Fenwick, R.C., and Nguyen, T.H. "Reinforced Concrete Beam Column Joints for Seismic Loading", UASE Report No. 220, Jan. 1981.

(7) Beckingsale, C.W., "Post Elastic Behaviour of Reinforced Concrete Beam-Column Joints" Research Report $80 / 20$ University of Canterbury August 1980.

(8) Fenwick, R.C. and Fong, A., "The Behaviour of Reinforced Concrete Beams under Cyclic Loading" UASE Report No. 176, Dec. 1979.

\section{APPENDIX 1 DETAILS FOR UNIT 2:}

BEAMS -

$b=250 \mathrm{~mm} \quad d=455 \mathrm{~mm} \quad \mathrm{f}_{\mathrm{C}}^{\prime}=36.4 \mathrm{MPa}$

$A_{S}=A_{S}^{\prime}=2-D 28+1-D 24$

$\mathrm{M}_{\mathrm{u}}$ (theoretical $=199.7 \mathrm{kNm} \quad \mathrm{f}_{\mathrm{y}}=278 \mathrm{MPa}$

$\mathrm{v}_{\mathrm{u}}($ theoretical $)=110.0 \mathrm{kN}$

$v_{u}=0.97 \mathrm{MPa}\left(0.16 \sqrt{\mathrm{f}_{\mathrm{C}}^{\top}}\right)$

stps. - 2 legs - Rl0 + $1 \operatorname{leg}$ R6 @ $100 \mathrm{c} / \mathrm{c}$

$\mathrm{v}_{\mathrm{S}}=232.4 \mathrm{kN}$ at $\mathrm{f}_{\mathrm{Y}}=275 \mathrm{MPa}$

COLUMNS -

designed to remain elastic under all conditions

Theoretical beam load at lst yield of col. steel is $228 \mathrm{kN}$.

\section{SUSTAINED LOADS -}

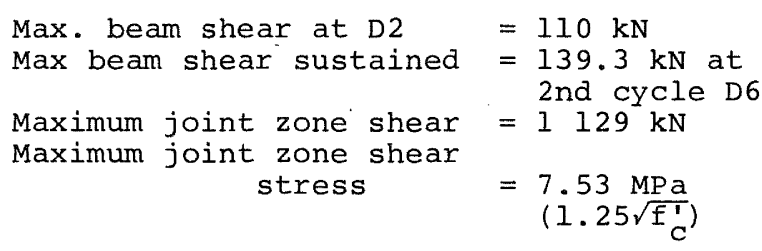

\section{JOINT ZONE REINFORCEMENT -}

$$
\begin{aligned}
& \text { Std joint }-N Z S 3101 \\
& A_{j h}=4100 \mathrm{~mm}^{2} \mathrm{f}_{\mathrm{y}}=275 \mathrm{MPa} \\
& A_{j v}=1108 \mathrm{~mm}^{2} \mathrm{f}_{\mathrm{y}}=380 \mathrm{MPa}
\end{aligned}
$$

(2) Elastic joint NZS 3101

$$
\begin{aligned}
& A_{j h}=1935 \mathrm{~mm}^{2} \mathrm{f}_{y}=275 \mathrm{MPa} \\
& A_{j v}=1108 \mathrm{~mm}^{2} \mathrm{f}_{y}=380 \mathrm{MPa}
\end{aligned}
$$

(3) Area provided

$$
\begin{aligned}
& A_{j h}=2513 \mathrm{~mm}^{2} \mathrm{f}_{y}=300 \mathrm{MPa} \\
& A_{j v}=1885 \mathrm{~mm}^{2} \mathrm{f}_{y}=409 \mathrm{MPa}
\end{aligned}
$$

(4) Apparent area required (see text)

$$
\begin{aligned}
& A_{j h}=1185 \mathrm{~mm}^{2} \mathrm{f}_{\mathrm{y}}=300 \mathrm{MPa} \\
& A_{j v}=750 \rightarrow 1350 \mathrm{~mm}^{2} \mathrm{f}_{\mathrm{y}}=380 \mathrm{MPa}
\end{aligned}
$$

